\title{
Factors influencing infection of Acacia mearnsii by the wilt pathogen Ceratocystis albifundus in South Africa
}

\author{
R. N. Heath ${ }^{1}$, M. van der Linde ${ }^{2}$, H. Groeneveld ${ }^{2}$, B. D. Wingfield ${ }^{1}$, M. J. Wingfield ${ }^{1}$, J. Roux ${ }^{3}$
}

(1) Department of Genetics, Tree Protection Co-operative Programme (TPCP), Forestry and Agricultural Biotechnology Institute (FABI), University of Pretoria, Pretoria, South Africa

(2) Department of Statistics, University of Pretoria, Pretoria, South Africa

(3) Department of Microbiology and Plant Pathology, Tree Protection Co-operative Programme (TPCP), Forestry and Agricultural Biotechnology Institute (FABI), University of Pretoria, Pretoria 0002, South Africa

\section{J. Roux}

Email: jolanda.roux@fabi.up.ac.za

\begin{abstract}
It is well known that species of Ceratocystis, which cause canker and wilt diseases on trees, require wounds for infection. In this regard, a number of physical and environmental factors influence the success of wound colonization by these fungi. The aim of this study was to consider the influence of wound age, stem diameter and colonization of wounds by Ophiostoma quercus on the success of infection by Ceratocystis albifundus, an important wilt pathogen of Acacia mearnsii in southern and eastern Africa, under field conditions. This was performed by doing controlled inoculations on Acacia mearnsii trees, of different diameters, with $C$. albifundus at different time intervals after wounding and after pre-inoculation of wounds with $O$. quercus at the time of wounding. The success of infection by $C$. albifundus decreased significantly from $8 \mathrm{~h}$ after wounding and was higher on stems of greater diameter. Pre-infection of wounds by O. quercus reduced the infection success of $C$. albifundus. The overall results showed that managing wounds created during forestry operations by treating wounds with naturally occurring, non-virulent fungi, such as $O$. quercus, could reduce the prevalence of infections by C. albifundus.
\end{abstract}

\section{Introduction}

Ceratocystis albifundus De Beer, M.J. Wingf. \& Morris (Ascomycetes, Microascales) is the causal agent of Ceratocystis wilt and die-back of non-native plantation-grown Acacia mearnsii De Wild. trees in southern and eastern Africa and is considered the most important pathogen of $A$. mearnsii trees in Africa (Morris et al. 1993; Wingfield et al. 1996; Roux and Wingfield 1997; Roux et al. 2005). The disease was first reported on A. mearnsii in South Africa (Morris et al. 1993), but it has subsequently also been recorded from Uganda (Roux and Wingfield 2001), Kenya and Tanzania (Roux et al. 2005). Symptoms of infection include gum exudation, wood-discoloration, stem cankers, rapid wilting and tree death (Morris et al. 1993; Roux et al. 1999). The fungus has been reported from native tree species in Africa, but has not been reported to cause disease on its native hosts (Roux et al. 2007).

Ceratocystis spp. require wounds for infection (Bretz 1952; Norris 1953; DeVay et al. 1963; Kile 1993). Such wounds can arise from wind (Roux et al. 2007), hail damage (Roux et al. 1995), growth cracks (Teviotdale and Harper 1991), insect and animal feeding (Walter 1946; Bretz 1952; 
DeVay et al. 1963), harvesting (Teviotdale and Harper 1991; Marin et al. 2003) and silvicultural practices such as grafting and pruning (Walter 1946; Teviotdale and Harper 1991; Dunlop and Goodricke 2000). Success of infection is dependent on a number of physical and environmental factors. For example, species in the Ceratocystis fimbriata sensu lato (s.l.) species complex are able to infect their hosts when viable fungal propagules are deposited onto bark wounds (DeVay et al. 1968). Other Ceratocystis spp., such as Ceratocystis fagacearum (Bretz) Hunt, can only infect if viable fungal propagules are deposited onto freshly exposed wood of the host (Kuntz and Drake 1957). Temporal factors also affect the success of infection by Ceratocystis spp. For example, Kuntz and Drake (1957) showed that $C$. fagacearum could not cause infection when wounds were older than $24 \mathrm{~h}$. Climatic factors such as temperature and relative humidity have also been shown to influence germination of spores and infection by Ceratocystis spp. (Cole and Fergus 1956). Gibbs (1980), showed that colonization of wounds by the saprophytic fungus, Ophiostoma piceae (Munch) H. Sydow \& Sydow, prior to infection by C. fagacearum, prevented colonization by the pathogen.

Ceratocystis spp. have evolved several strategies to reach wounds and subsequently infect trees. The most common of these is through associations with insects including bark beetles (Coleoptera: Scolytidae) (Webber and Gibs 1989; Kirisits 2004), nitidulid beetles (Coleoptera: Nitidulidae) (Himelick and Curl 1958; Moller and DeVay 1968; Harrington 1987) and flies (Moller and DeVay 1968; Hinds 1972). These fungi are morphologically adapted to insect dispersal having their ascospores in sticky drops at the apices of long-necked sporocarps (Dowding 1984). Many species of Ceratocystis, particularly those not associated with bark beetles (Webber and Gibs 1989; Kirisits 2004), also produce fruity aromas that attract insects that subsequently visit fresh wounds on trees. In this regard, $C$. albifundus has recently been reported to be associated with nitidulid beetles (Carpophilus spp. and Brachypeplus spp.) that visit wounds on native and non-native trees in South Africa (Heath et al. 2009).

Infection of $A$. mearnsii by $C$. albifundus has been associated with hail wounds, as well as with pruning wounds on these trees (Roux et al. 1995). Acacia mearnsii trees typically require corrective pruning to improve growth form after establishment and to correct damage caused by animal grazing (Dunlop and Goodricke 2000). Wounds arising from these operations provide ideal infection sites for C. albifundus.

Although selection and breeding for resistance against the disease caused by C. albifundus has been promoted, the fungus remains one of the most important pathogens of $A$. mearnsii in South Africa. Therefore, an understanding of the factors involved in the successful infection of wounds by $C$. albifundus could contribute to improved disease management options in plantations.

In this study we aimed: (i) to consider the influence of wound age on the success of infection by $C$. albifundus under field conditions; (ii) investigate the possible influence of the colonization of wounds by the commonly occurring wound-infecting Ophiostoma quercus (Georgév.) Nannf. (De Beer et al. 2003) on the success of infection by C. albifundus under field conditions; and (iii) to consider whether stem diameter affects the infection success of $C$. albifundus.

\section{Materials and Methods}

\section{Preparation of inoculum}

An isolate (CMW4095) of C. albifundus collected in 1998 from diseased A. mearnsii in South Africa was selected for artificial inoculations. Only one isolate was used for the study as low variance in virulence between isolates of $C$. albifundus was proven by De Beer (1994). An $O$. quercus isolate (CMW24164), collected from a 4-week-old wound on an A. mearnsii stump in 2006, 
also in South Africa, was selected for tests to consider the effect of pre-infection by this fungus on the infection success of $C$. albifundus. Both isolates are maintained in the culture collection (CMW) of the Forestry and Agricultural Biotechnology Institute (FABI), University of Pretoria, South Africa.

Pure cultures of the test isolates were grown on $2 \%(\mathrm{w} / \mathrm{v})$ malt extract agar (MEA) (Biolab, Midrand, South Africa) supplemented with Streptomycin sulphate $(0.001 \mathrm{~g} /$ volume; SIGMA, Steinheim, Germany) and incubated at $25^{\circ} \mathrm{C}$ under natural day/night conditions for 7 days prior to inoculation. Spore suspensions were made by washing spores from the surface of 7-day old cultures, with sterile water. Concentrations of spores were adjusted to $1 \times 106$ spores $/ \mathrm{ml}$ with sterile water using a Neubauer 1/100 mm haemocytometer (BEOCO, Hamburg, Germany). Suspensions were prepared no longer than $\sim 60 \mathrm{~min}$ before inoculation and were maintained at $\sim 5^{\circ} \mathrm{C}$ prior to application. Viability of the spores in the suspensions was confirmed by plating $1 \mathrm{ml}$ of spore suspension onto $2 \%(\mathrm{w} / \mathrm{v})$ MEA at the time of inoculation and confirming growth after 5 days.

\section{Wounding and inoculation of trees}

The study was conducted in a 2-year-old stand of $A$. mearnsii situated $35 \mathrm{~km}$ east of Pretoria, South Africa (S $25^{\circ} 23^{\prime} 38.3^{\prime \prime}$ E $\left.028^{\circ} 37^{\prime} 19.5^{\prime \prime}\right)$. The inoculation study was performed using a completely randomised design with regard to treatments as well as the diameter of tree stems. Trees ranging from 10 to $32 \mathrm{~mm}$ in diameter were wounded by cutting the stems $50 \mathrm{~cm}$ above the soil surface with pruning shears, thereby simulating stem reduction practices applied in silvicultural regimes for $A$. mearnsii cultivation in South Africa (Fig. 1a). This method produced a stub with a flush cut exposing the xylem cells of the stems. Inoculations commenced in March 2007 (late summer) and the study was completed in May 2007 (autumn), thus also consistent with the time at which corrective pruning often occurs.

A total of 400 trees were pruned for the experiment. Twenty different treatments were applied, with each treatment applied to 20 trees. The 20 treatments included a water control (negative control), a positive control with $C$. albifundus, a positive control with $O$. quercus and a combination of $C$. albifundus and $O$. quercus inoculated at wounding. Eight treatments included those where $C$. albifundus was inoculated onto wounds 2, 6, 8, 24, 48 (2 days), 124 (5 days), 196 (8 days) and 346 (14 days) hours after wounding. The remaining eight treatments were fresh wounds which were inoculated with $O$. quercus at the time of wounding, followed by inoculation with $C$. albifundus at 2, 6, 8, 24, 48 (2 days), 124 (5 days), 196 (8 days) and 346 (14 days) hours after wounding. Inoculations were made by dispensing $2-\mathrm{ml}$ spore suspensions directly onto the wounds using disposable syringes. The entire experiment was repeated once consecutively.

\section{Assessment of infection}

The experiments were terminated 6 weeks after each treatment commenced as this time period has been shown to be sufficient for disease development on trees of similar size under field conditions in South Africa (Roux et al. 1999). Inoculated stubs were collected by cutting the stems at the soil surface and transporting the samples in separate plastic bags to the laboratory. In the laboratory, the diameter of each stem was measured and the bark removed. Every inoculated wound was assessed visually for the presence or absence of vascular discoloration. Re-isolations were performed to correlate with visual assessment of $C$. albifundus infection. 

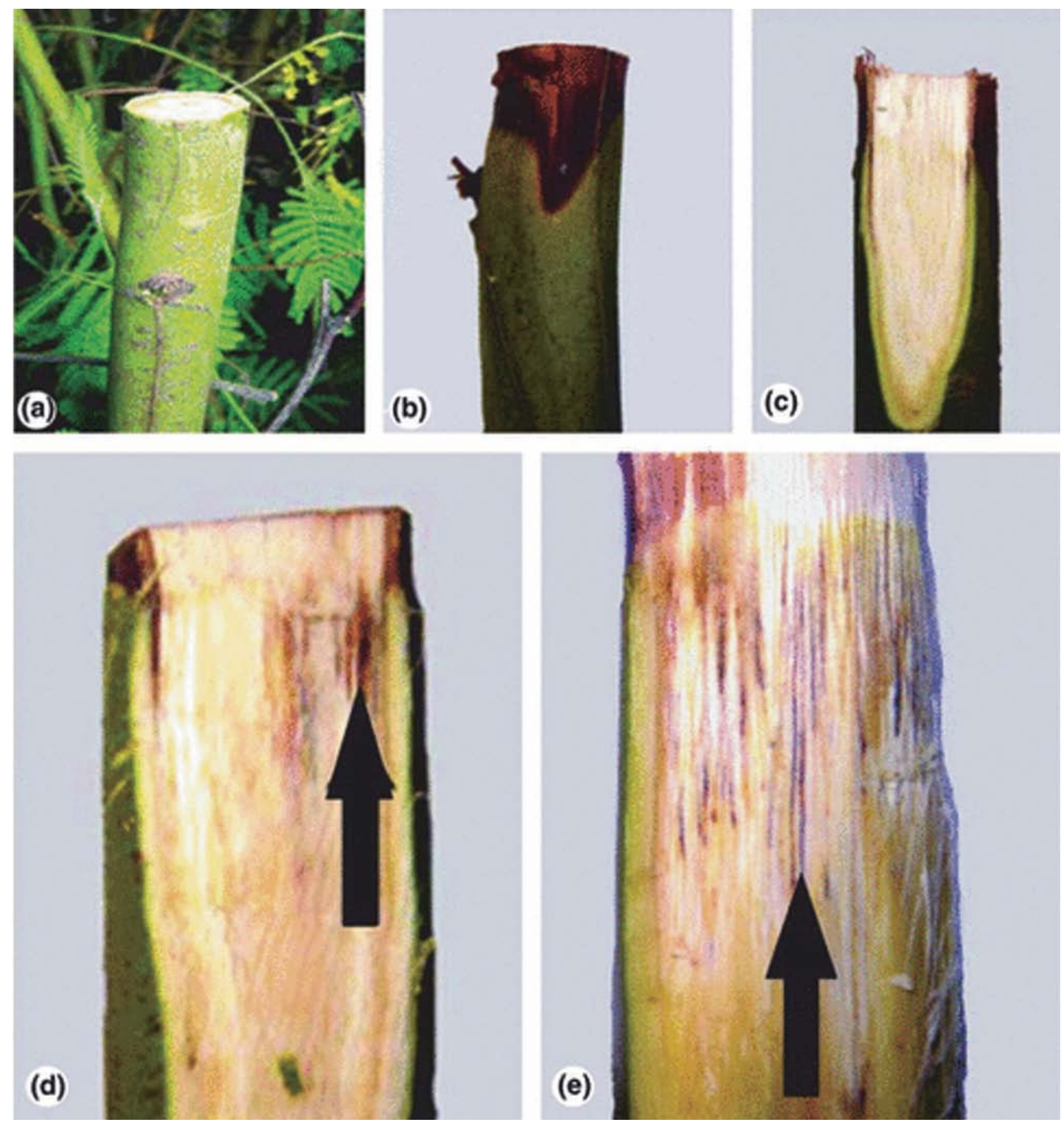

Figure 1. Wound morphology and symptoms of infection on Acacia mearnsii. (a) typical wound made for the inoculation; (b) external symptoms including dying of the tips of the stems; (c) water control showing no signs of infection; (d) vascular streaking caused by Ceratocystis albifundus (indicated by arrow); (e) vascular streaking caused by Ophiostoma quercus (indicated by arrow) on positive treatment with $O$. quercus.

\section{Statistical analyses}

Statistical analyses were performed using sas version 8.2 (SAS Statistical Software 2001). The infection data were converted to binary format with the presence of infection represented by a ' 1 ' and the absence of infection represented by ' 0 '. Because this response variable was binary, a logistic model could be applied to reproduce the logit as a linear model of the predictor variables. The predictor variables were treatment (a categorical variable with 20 levels), replicate (a categorical variable with two levels) and tree diameter (a continuous variable). The logistic analysis models the variable $\operatorname{lin}\{\mathrm{p} /(1-\mathrm{p})\}$, the logit, as a linear function of the predictor variables, where $\mathrm{p}$ 
is the probability of a specific combination of predictor values to yield an infection.

The significance of each predictor to predict the logit was calculated. The concordance percentage was calculated to serve as a measure of the 'goodness of fit' of the applied model. Confidence intervals for the true model parameters were calculated using the estimated parameters and their standard errors. Furthermore, to provide for specific chosen combinations of predictor values (treatment, replicates and tree diameter), not present in the data, such combinations were added to the dataset whereas the response variable was absent. This was performed to exclude the 'spiked' observations when the model was fitted, and to include them when estimated p-values were calculated for the specific added combinations. Finally, 95\% confidence intervals were calculated for the p-values for the 'spiked' observations.

\section{Results}

\section{Assessment of infection}

The only exterior symptoms observed on inoculated stems, 6 weeks after inoculation, were death of the tips of the stems (Fig. 1b), yellowing of the bark and staining of the wood. Ceratocystis infection was distinguished from infection by O. quercus based on the fact that C. albifundus causes light to dark brown streaking (Fig. 1d) whereas $O$. quercus resulted in stain, when present, having a distinct blue colour (Fig. 1e). The majority (95\%) of the 40 negative water controls (Fig. 1c) showed no symptoms of $C$. albifundus or $O$. quercus infection. Those control treatments that did show infection (5\%) were considered to be due to natural infection since C. albifundus naturally occur in the Gauteng Province (Roux et al. 2007). Re-isolation of C. albifundus from infected stems followed a similar trend to infection assessed visually (Table 1). The chi-square probability value showed significant treatment differences within the total dataset $(p<0.0001)$. The predictor variable, replicate, had a significant effect on the analyses $(p=0.0008)$. This could be due to the trees used in the repeat trial entering the dormancy period due to the change in season (Robinson et al. 2004). However, no interaction existed between the predictor variables treatment and replicates $(\mathrm{p}=0.4745)$, therefore treatment means could be calculated across replicates.

\section{Time after wounding}

The time after wounding had a significant influence on the infection success of C. albifundus. The greatest number of stems with symptoms of $C$. albifundus infection was observed in the 6-h treatment where $C$. albifundus was inoculated alone, with 31 of the 40 trees (77.5\%) showing infection. Infection of stems inoculated with C. albifundus at the time of wounding, 3, 6 and $8 \mathrm{~h}$ after wounding was significantly higher than that of all other treatments $(p<0.0001$ to $p=0.0344)$. The levels of infection of stems that were inoculated with C. albifundus at 124, 196 and $346 \mathrm{~h}$ after wounding were not significantly different from the control treatments for this experiment, nor did they differ significantly from each other (Fig. 2).

\section{Pre-inoculation with Ophiostoma quercus}

Pre-inoculation of stems with $O$. quercus had a significant influence on the infection success of $C$. albifundus. Stems inoculated with $O$. quercus and C. albifundus concurrently at the time of wounding exhibited the highest levels of infection and differed significantly from all other treatments. All other treatments inoculated with $O$. quercus at the time of wounding, and $C$. albifundus at different time intervals thereafter, were significantly different from the control treatment (Fig. 3). Pre-inoculation with O. quercus at time of wounding and with $C$. albifundus at $196 \mathrm{~h}$ was not significantly different from the control treatments. All other treatments differed significantly from the control treatments. 
Table 1. Comparison of Ceratocystis albifundus isolated from vascular streaking to visual infection assessed.

Treatment $\quad \begin{gathered}\text { Number of visual } \\ \text { symptoms observed }\end{gathered} \quad \begin{gathered}\text { Number of Ceratocystis } \\ \text { albifundus isolates obtained }\end{gathered}$

$\begin{array}{lrr}\text { Water control } & 2 & 0 \\ \text { Ceratocystis albifundus, } 0 \mathrm{~h} & 30 & 10 \\ \text { Ophiostoma quercus, } \mathrm{O} \mathrm{h} & 15 & 3 \\ \text { C. albifundus and } O \text {. quercus, } 0 \mathrm{~h} & 28 & 5 \\ \text { C. albifundus, } 2 \mathrm{~h} & 28 & 9 \\ \text { O. quercus, } 2 \mathrm{~h} & 15 & 0 \\ \text { C. albifundus, } 6 \mathrm{~h} & 31 & 9 \\ \text { O. quercus, } 6 \mathrm{~h} & 16 & 1 \\ \text { C. albifundus, } 8 \mathrm{~h} & 29 & 5 \\ \text { O. quercus, } 8 \mathrm{~h} & 11 & 0 \\ \text { C. albifundus, } 24 \mathrm{~h} & 18 & 2 \\ \text { O. quercus, } 24 \mathrm{~h} & 9 & 0 \\ \text { C. albifundus, } 48 \mathrm{~h} & 9 & 0 \\ \text { O. quercus, } 48 \mathrm{~h} & 8 & 0 \\ \text { C. albifundus, } 124 \mathrm{~h} & 5 & 0 \\ \text { O. quercus, } 124 \mathrm{~h} & 10 & 0 \\ \text { C. albifundus, } 196 \mathrm{~h} & 6 & 0 \\ \text { O. quercus, } 196 \mathrm{~h} & 5 & 0 \\ \text { C. albifundus, } 346 \mathrm{~h} & 3 & 0 \\ \text { O. quercus, } 346 \mathrm{~h} & 7 & \end{array}$

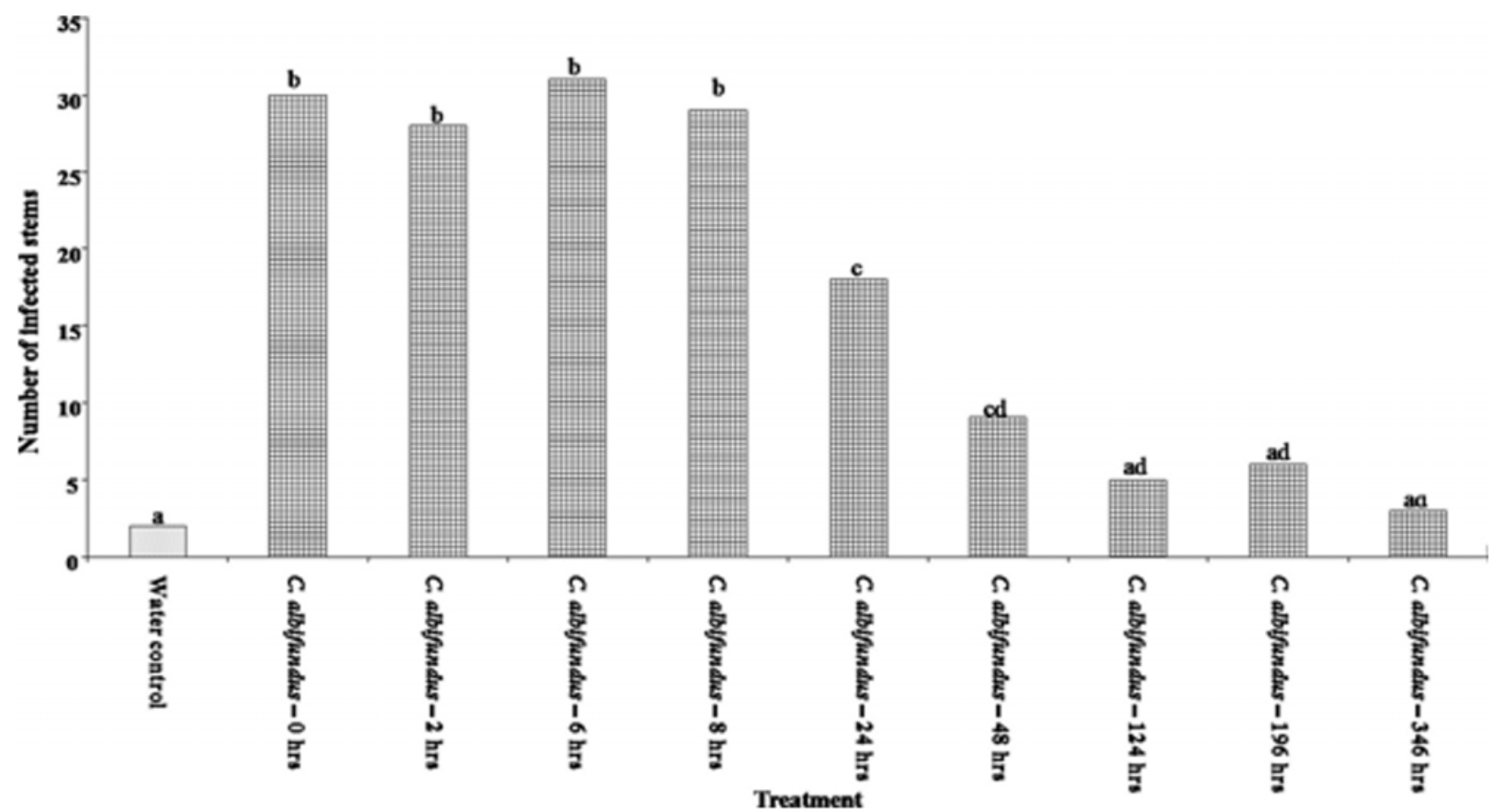

Figure 2. Number of horizontal stem cuts (wounds) infected with Ceratocystis albifundus assessed visually for each treatment. Different letters above bars indicate treatment results significantly different from each other at a 5\% significance level. Figure shows combined data for both experiments $(2 \times 20$ trees $)$. 


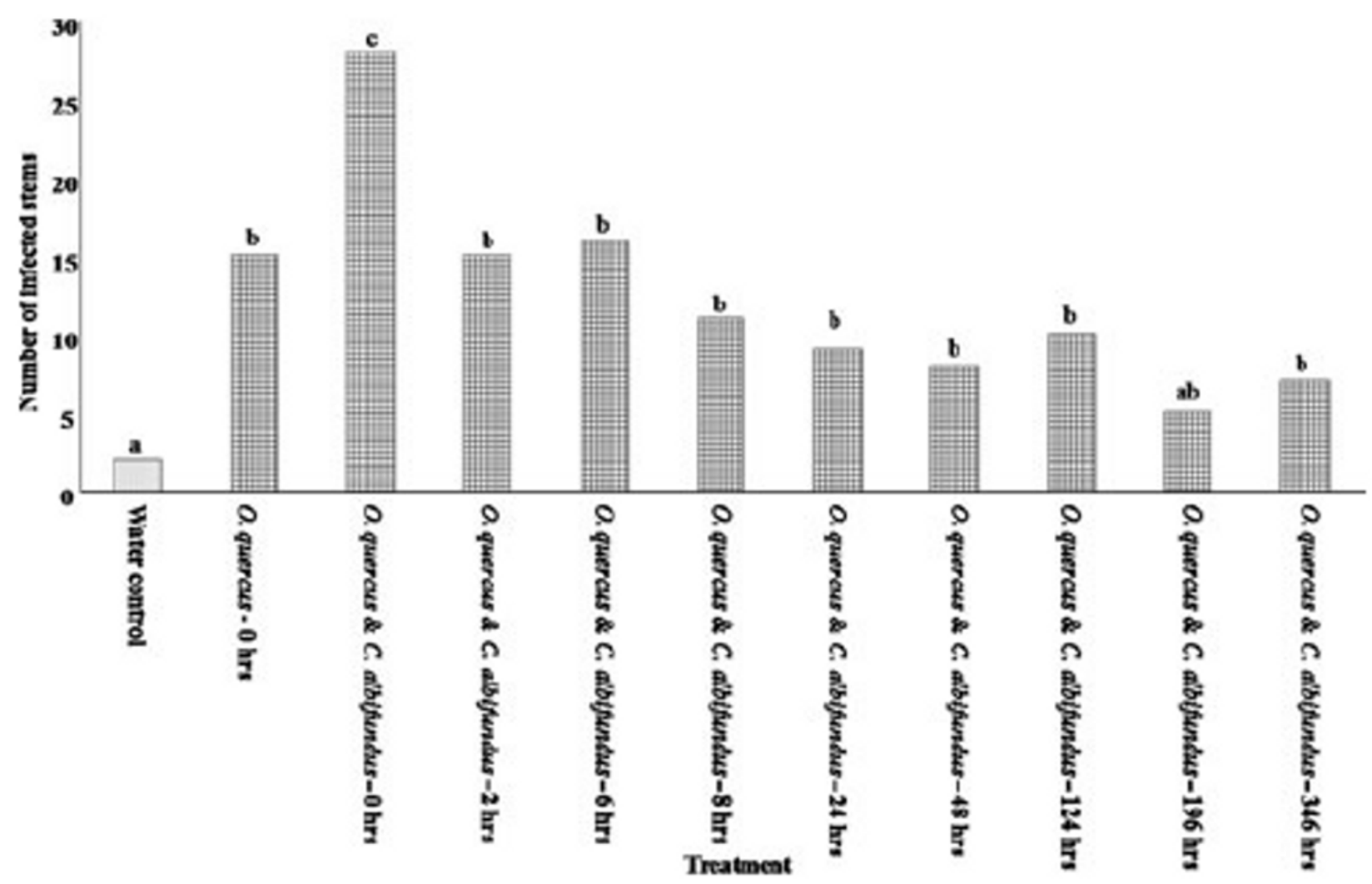

Figure 3. Number of horizontal stem cuts (wounds) infected with Ceratocystis albifundus assessed visually for each treatment. Different letters above bars indicate treatment results significantly different from each other at a 5\% significance level. Figure shows combined data for both experiments $(2 \times 20$ trees $)$.

\section{Influence of stem diameter on infection}

The diameter of the stems, and thus surface area of the wound exposed to infection, had a significant influence on the infection success of $C$. albifundus $(\mathrm{p}=0.0002)$. The analysis of maximum likelihood estimates produced an estimate value of 0.0617 for tree diameter as a predictor variable with 1 degree of freedom (Fig. 4). This indicated that with every $10 \mathrm{~mm}$ increase in stem diameter, the probability of infection by $C$. albifundus increased by $0.62 \%$.

\section{Discussion}

Results of this study showed clearly that infection of wounds on A. mearnsii by C. albifundus is strongly influenced by the condition of the wounds. Wounds became less susceptible to infection over time and after $24 \mathrm{~h}$ they had a very low level of susceptibility. Likewise, pre-inoculation of wounds with $O$. quercus significantly decreased the ability of $C$. albifundus to infect wounds. Potential of infection also increased as the size of the stems increased.

Loss of susceptibility to infection by $C$. albifundus with increasing wound age was not surprising. Similar results have been found in many studies of pathogens, including C. fimbriata, Leucostoma cincta and Leucostoma persoonii, which infect woody plants (Bostock and Middleton 1987; Biggs 1989; Teviotdale and Harper 1991). Specifically in the case of Ceratocystis, the results of this study are similar to those on $C$. fagacearum where wounds on oak trees are typically found not to be susceptible to infection after 24 h (Morris et al. 1955; Kuntz and Drake 1957; Gibbs 1980). 


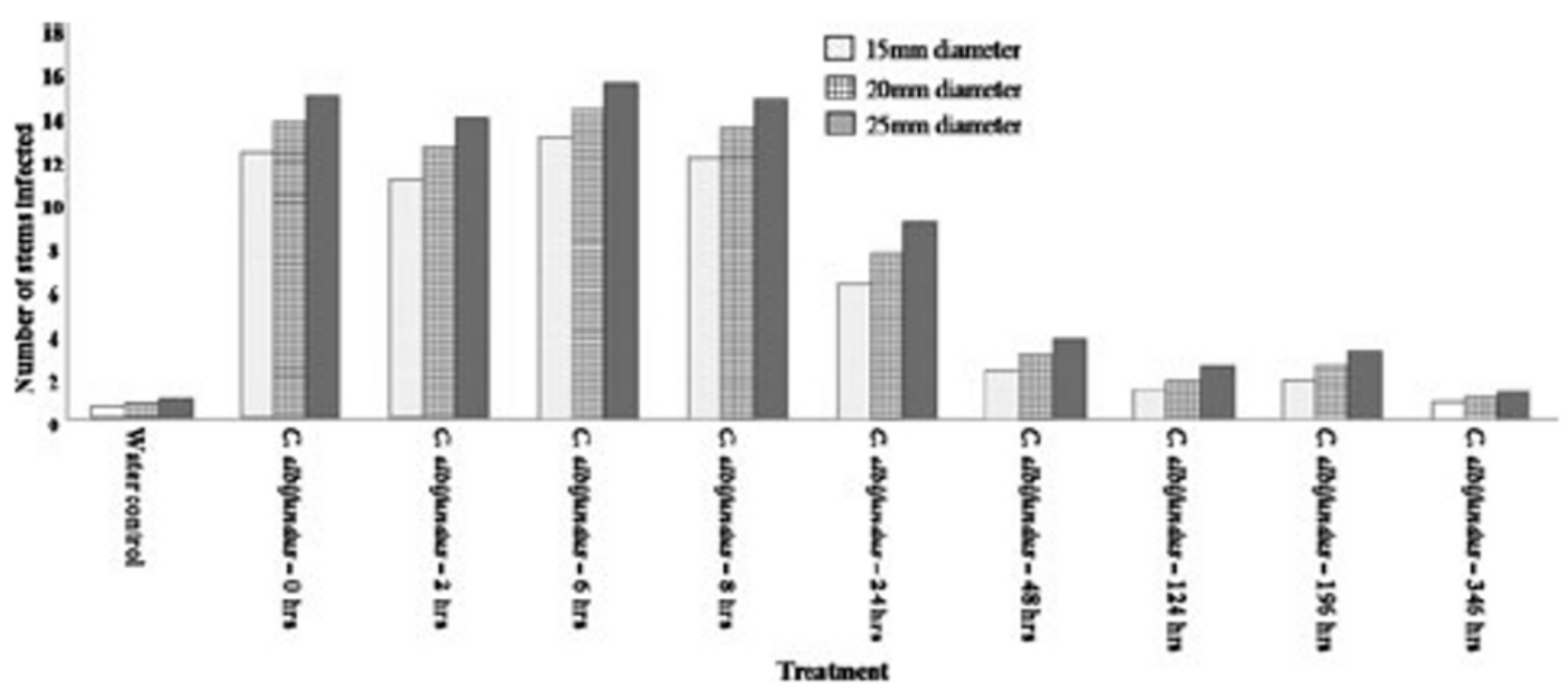

Figure 4. The effect of diameter on infection success of Ceratocystis albifundus on horizontal stem cuts (wounds) obtained from analysis for specific chosen combinations of the predictor values (treatment, replicates and tree diameter) at a 5\% significance level obtaining a percentage concordance of $80.5 \%$ and Wald chi-squared value of 13.67 and $p=0.0002$. Figure shows combined data for both experiments $(2 \times 20$ trees $)$.

The present study did not investigate the possible reasons why wound susceptibility decreases with time. Previous studies attributed loss of susceptibility of wounds to C. fimbriata on Almond trees to the fact that the thin film of moisture required on the wound for the germination of spores disappears with time. Other studies have attributed the increase in resistance of wounds to infection with time to the accumulation of an impervious lingo-suberized layer (Biggs 1984, 1985a,b, 1989; Oven et al. 1999; Stobbe et al. 2002; Robinson et al. 2004). Numerous authors have stated that this layer is responsible for preventing moisture loss from the wound as well as preventing fungal infection (Biggs 1992; Woodward 1992). The formation of a necrophylactic periderm has also been reported as a wound response that could prevent fungal infection (Biggs 1985a). It is, however, unlikely that the formation of the necrophylactic periderm is the primary defence against fungal infection as this layer only forms after the impervious lingo-suberized layer has formed (Woodward 1992; Oven and Torelli 1994; Oven et al. 1999).

Pre-inoculation of wounds with $O$. quercus had a significant effect on infection with C. albifundus. Thus, colonization of fresh wounds by $O$. quercus approximately $2 \mathrm{~h}$ prior to infection by $C$. albifundus could reduce the chance of infection by the pathogen significantly. In a similar study, Gibbs (1980) showed that where $O$. piceae was inoculated onto fresh wounds approximately $24 \mathrm{~h}$ prior to $C$. fagacearum, the chance of infection by the pathogen was greatly reduced. Ophiostoma quercus was selected for the present study because it is commonly found on wounds on $A$. mearnsii trees (R. N. Heath, unpublished data) and has not been reported to decrease the value or structural integrity of the timber. Damage caused by sapstain fungi such as O. quercus have been reported to be cosmetic (Seifert 1993). Another consideration was that Ophiostoma spp. have a biology similar to that of Ceratocystis spp. and are also carried to wounds by insects (Brasier 1990; Kirisits 2004). Gibbs (1980) suggested that colonization of wounds by O. piceae may be common in nature, reducing the natural occurrence of oak wilt. The same situation seems to be possible in South Africa in the case of $C$. albifundus infection and the colonization of wounds with $O$. quercus.

The diameter of the stems inoculated in this study had a significant effect on the infection success of $C$. albifundus. As the stem diameter increased, and thus the size of the exposed wound (horizontal cut) surface area, the probability of infection increased. This could be due to a more rapid drying of the smaller stems compared with the larger stems. The fact that stem diameter has 
an influence on the infection success of $C$. albifundus makes the results of this study applicable to the prescribed pruning protocols for $A$. mearnsii trees in South Africa. Current silvicultural prescriptions for the management of $A$. mearnsii suggest that pruning should be undertaken on stems 2-4 m tall (Dunlop and Goodricke 2000). If the age at which pruning conducted is reduced, the diameter of the stems would be smaller and infection be less likely.

Successful management of plantation forest diseases relies on a combination of selection and breeding and sound silvicultural practices. The results obtained in this study could assist forestry companies in southern and eastern Africa in formulating silvicultural regimes that could reduce the impact of C. albifundus infection and mortality after pruning. The results obtained in this study could also be applied to better management of numerous tree growing industries. Furthermore, this study also raises the possibility of using $O$. quercus to reduce the infection of recently cut stems by C. albifundus. Although this study supports findings obtained in previous studies using other Ceratocystis spp., this is the first study of its kind on the African continent and the first to provide possible management prescriptions for the fully regulated forestry management system followed in numerous countries world-wide.

\section{Acknowledgments}

We thank Mr J. Hood and Ms A. Brevis for providing the study area. Francois van der Walt, Gavin Hunter and Marelize van Wyk provided valuable technical assistance. The South African Department of Trade and Industry's (THRIP) initiative, the National Research Foundation (NRF), the DST/NRF Centre of Excellence in Tree Health Biotechnology (CTHB) and the Tree Protection Co-operative Programme (TPCP) provided funding to undertake this research.

\section{Literature Cited}

Biggs, A. R., 1984: Intercellular suberin: occurrence and detection in tree bark. Int. Assoc. Wood Anat. Bull. 5, 243-248.

Biggs, A. R., 1985a: Detection of impervious tissue in tree bark with selective histochemistry and fluorescence microscopy. Stain Technol. 60, 299-304.

Biggs, A. R., 1985b: Suberised boundary zones and the chronology of wound response in tree bark. Phytopathology 75, 1191-1195.

Biggs, A. R., 1989: Temporal Changes in the infection court after wounding of peach bark and their association with cultivars in infection by Leucostoma persoonii. Phytopathology 79, 627-630.

Biggs, A. R., 1992: Anatomical and physiological responses of bark tissues to mechanical injury. In: Defense Mechanisms of Woody Plants Against Fungi. Ed. by Blanchette, R. A.; Biggs, A. R. Berlin: Springer Verlag, pp. 13-40.

Bostock, R. M.; Middleton, G. E., 1987: Relation of wound periderm formation to resistance to Ceratocystis fimbriata in almond bark. Phytopathology 77, 1174-1180.

Brasier, C. M., 1990: China and the origins of Dutch Elm disease: and appraisal. Plant Pathol. 39, $5-16$.

Bretz, T. W., 1952: The ascigerous stage of the oak wilt fungus. Phytopathology 42, 435-437. 
Cole, H. J.; Fergus, C. L., 1956: Factors associated with germination of Oak wilt fungus spores in wounds. Phytopathology 46, 159-163.

De Beer, C., 1994: Ceratocystis fimbriata with special reference to its occurrence as a pathogen of Acacia mearnsii in South Africa. MSc Thesis. University of the Orange Free State, Bloemfontein, South Africa. pp. 73-89.

De Beer, Z. W.; Wingfield, B. D.; Wingfield, M. J., 2003: The Ophiostoma piceae complex in the southern hemisphere: a phylogenetic study. Mycol. Res. 107, 469-476.

DeVay, J. E.; Lukezic, F. L.; English, W. H.; Trujillo, E. E., 1963: Ceratocystis canker of stone fruit trees. Phytopathology 53, 873.

DeVay, J. E.; English, W. H.; Lukezic, F. L.; Moller, W. I.; Trujillo, E. E., 1968: Ceratocystis canker of deciduous fruit trees. Phytopathology 58, 949-956.

Dowding, P., 1984: The evolution of insect-fungus relationships in the primary invasion of forest timber. In: Invertebrate-Microbial Interactions. Ed. by Anderson, J. M.; Rayner, A. D. M.; Walton, D. W. H. New York: Cambridge University Press.

Dunlop, R. W.; Goodricke, T. G., 2000: Black Wattle (Acacia mearnsii). In: South African Forestry Handbook 2000. Ed. by Owen, D. L. Menlopark, South Africa: The South African Institute for Forestry, pp. 124-127.

Gibbs, J. N., 1980: Role of Ceratocystis piceae in preventing infection by Ceratocystis fagacearum in Minnesota. Trans. Br. Mycol. Soc. 74, 171-174.

Harrington, T. C., 1987: New combinations in Ophiostoma and Ceratocystis species with Leptographium anamorphs. Mycotaxon 28, 39-43.

Heath, R. N.; Van Wyk, M.; Wingfield, B. D.; Wingfield, M. J.; Roux, J., 2009: Insects associated with Ceratocystis albifundus in South Africa. Environ. Entomol. 38, 356-364.

Himelick, E. B.; Curl, E. A., 1958: Transmission of Ceratocystis fagacearum by insects and mites. Plant Dis. Rep. 42, 538-545.

Hinds, T. E., 1972: Insect transmission of Ceratocystis species associated with Aspen cankers. Phytopathology 62, 221-225.

Kile, G. A., 1993: Plant diseases caused by species of Ceratocystis sensu stricto and Chalara. In: Ceratocystis and Ophiostoma; Taxonomy, Ecology and Pathogenicity. Ed. by Wingfield, M. J.;

Seifert, K. A.; Webber, J. F. St Paul, MN: APS Press, pp. 173-183.

Kirisits, T., 2004: Taxonomy and systematics of bark and ambrosia beetles. In: Bark and Woodboring Insects in Living Trees in Europe, A Synthesis. Ed. by Lieutier, F.; Day, K. R.; Batisttisti, A.; Grégoire, J.-C.; Evans, H. F. The Netherlands: Kluwer Academic Publishers, pp. $181-235$.

Kuntz, J. E.; Drake, C. R., 1957: Tree wounds and long distance spread of Oak wilt. Phytopathology 47, 22.

Marin, M.; Castro, B.; Gaitan, A.; Preisig, O.; Wingfield, B. D.; Wingfield, M. J., 2003: 
Relationship of Ceratocystis fimbriata isolates from Colombian coffee-growing regions based on molecular data and pathogenicity. Phytopathology 151, 395-405.

Moller, W. J.; DeVay, J. E., 1968: Insect transmission of Ceratocystis fimbriata in deciduous fruit orchards. Phytopathology 58, 1499-1507.

Morris, C. L.; Thompson, H. E.; Hadley, B. L.; Davis, J. M., 1955: Use of radioactive tracer for investigation of the activity pattern of suspected insect vectors of the oak wilt fungus. Plant Dis. Rep. 39, 61-63.

Morris, M. J.; Wingfield, M. J.; De Beer, C., 1993: Gummosis and wilt of Acacia mearnsii in South Africa caused by Ceratocystis fimbriata. Plant Pathol. 42, 814-817.

Norris, D. N., 1953: Insect transmission of oak wilt in Iowa. Plant Dis. Rep. 37, 417-418.

Oven, P.; Torelli, N., 1994: Wound response of the bark in healthy and declining Silver firs (Abies alba). Int. Assoc. Wood Anat. J. 15, 407-415.

Oven, P.; Torelli, N.; Shortle, W. C.; Zupančič, M., 1999: The formation of a ligni-suberised layer and necrophylactic periderm in beech bark (Fagus sylvatica L.). Flora 194, 137-144.

Robinson, R. M.; Jensen, G. D.; Morrison, D. J., 2004: Necrophylactic periderm formation in the roots of western larch and Douglas-fir trees infected with Armillaria ostoyae I. The response to abiotic wounding in non-infected roots. For. Pathol. 34, 105-118.

Roux, J.; Wingfield, M. J., 1997: Survey and virulence of fungi occurring on diseased Acacia mearnsii in South Africa. For. Ecol. Manage. 99, 327-336.

Roux, J.; Wingfield, M. J., 2001: First report of Ceratocystis wilt of Acacia mearnsii in Uganda. Plant Dis. 85, 1029.

Roux, J.; Kemp, G. H. J.; Wingfield, M. J., 1995: Diseases of Black Wattle in South Africa - a review. Suid-Afrikanse Bosboutydskrif (changed to S. Afr. For. J.) 174, 35-40.

Roux, J.; Dunlop, R.; Wingfield, M. J., 1999: Susceptibility of elite Acacia mearnsii families to Ceratocystis wilt in South Africa. J. For. Res. 4, 187-190.

Roux, J.; Meke, G.; Kanyi, B.; Mwangi, L.; Mbaga, A.; Hunter, G. C.; Nakabonge, G.; Heath, R. N.; Wingfield, M. J., 2005: Diseases of plantation forestry tree species in eastern and southern Africa. S. Afr. J. Sci. 101, 409-413.

Roux, J.; Heath, R. N.; Labuschagne, L.; Kamgan Nkuekam, G.; Wingfield, M. J., 2007: Occurrence of the wattle wilt pathogen, Ceratocystis albifundus on native South African trees. For. Pathol. 37, 292-302.

SAS Statistical Software. 2001: SAS / STAT User's Guide, Version 8.2, Cary, NC, USA: SAS Institute Inc.

Seifert, K. A., 1993: Sapstain of commercial lumber by species of Ophiostoma and Ceratocystis. In: Ceratocystis and Ophiostoma; Taxonomy, Ecology and Pathogenicity. Ed. by Wingfield, M. J.; Seifert, K. A.; Webber, J. F. St. Paul, Minesota: APS Press, pp. 141-151. 
Stobbe, H.; Schmitt, U.; Eckstein, D.; Dujesiefken, D., 2002: Development stages and fine structure of surface callus formed after debarking of living trees (Tillia sp.). Ann. Bot. 89, 773-782.

Teviotdale, B. L.; Harper, D. H., 1991: Infection of pruning and small bark wounds in almond by Ceratocystis fimbriata. Plant Dis. 75, 1026-1030.

Walter, J. M., 1946: Canker stain of plane trees. Washington D.C.: USDA Circular, No. 742.

Webber, J. F.; Gibs, J. N., 1989: Insect dissemination of fungal pathogens of trees. In: Insect Fungus Interactions. 14th Symposium of the Royal Entomological Society of London in collaboration with the British Mycological Society. Ed. by Wilding, N.; Collins, N. M.; Hammond, P. M.; Webber, J. F. London: Academic Press.

Wingfield, M. J.; De Beer, C.; Visser, C.; Wingfield, B. D., 1996: A new Ceratocystis species defined using morphological and ribosomal DNA sequence comparisons. Syst. Appl. Microbiol. 19, 191-202.

Woodward, S., 1992: Responses of gymnosperm bark tissue to fungal infection. In: Defence Mechanisms of Woody Plants Against Fungi. Ed. by Blanchette, R. A.; Biggs, A. R. Berlin: Springer, pp. 62-75. 